\title{
Georg Simmel: una antropología filosófica
}

\section{Georg Simmel: A philosophical Anthropology}

\author{
EDUARDO GUTIÉRREZ GUTIÉRREZ \\ Universidad de Valladolid
}

\begin{abstract}
RESUMEN
En los últimos años se está produciendo una importante recuperación del pensamiento de Georg Simmel. Dicha importancia no radica sólo en el valor de Simmel como clásico de la filosofía, sino también en la imperiosa actualidad de sus teorías e ideas filosóficas y sociológicas. A estos esfuerzos de actualización del pensamiento simmeliano quiero sumar un estudio de las principales ideas de su antropología filosófica. El hecho de que podamos tomar su antropología como una síntesis y modernización de la tesis marxistas y nietzscheanas es una evidencia de la importancia que pueden tener las ideas de Simmel hoy día. Por lo tanto, el objetivo de este artículo es el de presentar las principales ideas de la antropología filosófica de Georg Simmel para, a partir de ellas, confeccionar un cuadro general de la estructura anímica del individuo moderno.
\end{abstract}

PALABRAS CLAVE:

SIMMEL; ANTROPOLOGÍA MATERIALISTA; ANTROPOLOGÍA FILOSÓFICA; MODERNIDAD.

\begin{abstract}
Recently there has been an important recovery of the thought of Georg Simmel. The importance of this recovery is not only due to the value of Simmel as classical philosophy; his is also due to the imperative present of his philosophical and sociological theories. I want to add to the efforts of simmelian thought update a study of the main ideas of his philosophical anthropology. The fact that we can take his anthropology as a synthesis and modernization of marxist and nietzschean thesis is an evidence of the importance that Simmel's ideas may have today.
\end{abstract}


This article is a presentation of the main ideas of the philosophical anthropology of Georg Simmel. From them, we will draw up a general picture of the psychic structure of the modern individual.

KEYWORDS

SIMMEL; MATERIALIST ANTHROPOLOGY; PHILOSOPHICAL ANTHROPOLOGY; MODERNITY.

\section{INTRODUCCIÓN}

Convengamos con Ortega y Gasset que la antropología filosófica o conocimiento del hombre es una ciencia cuya tarea consiste en mostrar los diferentes tipos de estructura anímica que subyacen a la diversidad de individuos y que caracterizan a cada época histórica (Ortega y Gasset, 2015 [1925]: 241). Se trata del estudio del ser del hombre. Pero como el hombre, ya lo veremos más adelante, no es sino que se está haciendo, el estudio del ser del hombre no es el estudio de algo dado y estático sino de una multiplicidad de tipos que son cristalización del hacer humano.

A pesar de la recuperación, revalorización y renovación del pensamiento simmeliano que se está realizando en los últimos años para aportar frescura y nuevas perspectivas en los debates de la filosofía contemporánea, hay un ámbito al que no se ha prestado la atención merecida: su antropología filosófica, fuertemente influenciada por Kant, Marx y Nietzsche. Solamente el hecho de que su concepción antropológica consista, como en su epistemología y ética, en una síntesis de las ideas ofrecidas por estos filósofos acerca del hombre y su lugar en el mundo debería ser razón más que suficiente para rehabilitar este ámbito del pensamiento de Georg Simmel. Con la intención de tal rehabilitación y recuperación realizamos este artículo.

La filosofía de Simmel es profundamente humanista y humana, esto es, antropológica. Humanista porque el ser humano en cuanto vida individualizada ocupa el lugar central de todas sus reflexiones, y humana porque su labor filosófico-sociológica se puede interpretar como un intento de rehabilitación del ámbito cultural a fin de devolverle a la subjetividad el lugar central perdido en beneficio de la «cultura objetiva». Los problemas epistemológicos, metafísicos, sociológicos, históricos y culturales refieren en último término al enigma de la subjetividad y a la pregunta de qué es el Hombre.

\section{EL HOMBRE, UN «SER DE DIFERENCIA».}

El hombre es «ser de diferencia» porque es un ser que se diferencia y que percibe diferencias. Las diferencias entre los individuos posibilitan la diversidad 
de intereses prácticos, de objetos de satisfacción de las necesidades y deseos particulares y de modos de vida (Kroker, 2003: 47).

Es también «ser de diferencia» porque, como dice Mundo, las diferencias internas del individuo constituyen su ser, organizan su conciencia y componen su estructura, igual que las diferencias entre los individuos participan en la construcción de la identidad social. A partir de la diferencia el individuo se organiza psíquicamente, aunque no es él mismo quien instaura esa diferencia. Es la vida en cuanto concepto metafísico y fuente ontológica la que le obliga a diferenciar distintos órdenes vitales: «La vida resultaría ser el proceso diferenciador; el hombre, un derivado» (Mundo, 2014: 3). Diferenciamos lo animal de lo humano porque en un primer momento de trascendencia vital la vida supera el nivel de la vida biológica y salta al nivel de la vida consciente, que después deviene en vida cultural. En su dinamismo la vida crea diferencias dividiéndose a sí misma. El sujeto consciente, el hombre en cuanto individualización de la vida, es en sí mismo una diferencia que resulta del ejercicio de fraccionamiento de la vida motivado por un deseo inherente de superarse a sí misma.

En Las grandes ciudades y la vida intelectual aclara la idea del hombre como «ser de diferencia», cuya definición más analítica refiere a su dimensión psíquica: «El hombre es un ser de diferencia; es decir, su conciencia es estimulada por la diferencia entre la impresión del momento y la anterior» (Simmel, 1978 [1903]: 12). Lo que capta no son impresiones sino las variaciones entre impresiones: son tantas las impresiones que recibe cada día el individuo de la gran ciudad y tan pequeñas y regulares las diferencias entre unas y otras que su conciencia se ve estimulada en muy menor grado. De ahí que el individuo moderno sea un hombre enajenado, porque pierde su condición de «ser de diferencia».

Impone la gran ciudad moderna un ritmo, tanto sensible como intelectual -en la aglomeración de impresiones, imágenes, discursos, pensamientos, etc.-, $\tan$ frenético que agota la individualidad del «ser de diferencia». La subjetividad se encuentra bajo amenaza de perecer ante la generalización social de la gran ciudad, cuidándose el individuo urbano de mostrar en público su personalidad interna. En cambio el hombre rural es capaz de estrechar mayores vínculos afectivos, no viéndose su subjetividad constantemente amenazada por la incesante confluencia de impresiones. Por eso en la ciudad la individualidad está más marcada, porque en todo momento ha de enfrentarse a la fuerza social que objetiva y homogeneiza lo diferente, subjetivo y excepcional (Simmel, 1978 [1903]: 13). La pérdida de la condición de «ser de diferencia» produce la disolución de la individualidad en la gran masa, la homogeneización de lo heterogéneo, y la pérdida de una floreciente diversidad (Kroker, 2003: 67). 


\section{LA TENSIÓN INDIVIDUO-SOCIEDAD.}

El hombre tiene deseo de ser diferente y alejarse del resto, pero al mismo tiempo tiene la necesidad de formar sociedad junto a los otros -y a pesar de los otros, lo que supone una novedad en el pensamiento simmeliano heredada de Marx: el conflicto como forma de socialización-. Sigue aquí Simmel la idea kantiana de una naturaleza humana dialógica: el Hombre es ser social pero también y al mismo tiempo insociable. El individuo se enfrenta a fuerzas y energías externas frente a las cuales trata de sobrevivir como diferencia y peculiaridad única, pero también busca y necesita la protección del grupo.

Esta tensión entre el deseo de individuación y el deseo de socialización toma forma en la ambivalencia que constituye la estructura anímica del individuo entre individualidad cualitativa o personalidad interna e individualidad cuantitativa o función social externa. La personalidad comprende el ámbito interno del yo y la función social el ámbito externo, que es el ámbito de la relación con los otros. Entre estas dimensiones psíquicas de la persona se va a mover la paradoja moderna que existe, según Simmel, al experimentar el individuo un aumento equivalente de libertad y de dependencia para con los otros y el producto de su trabajo: el individuo moderno es más libre como personalidad interna, pero más dependiente en cuanto función social.

En la modernidad, de acuerdo con esta tensión, la libertad individual se entiende sobre la base de la disociación personalidad-función social. Para preservar esta libertad el individuo busca el aseguramiento de su perímetro de intimidad con el aislamiento y la indiferencia hacia todo lo cualitativamente distinto y notable. Dos sujetos pueden entablar relación aunque ambas personalidades se mantengan aisladas la una de la otra, ya que lo que entra en relación, lo que a cada uno le interesa del otro, no es su subjetividad sino el papel que cumple dentro de la red de relaciones que compone la estructura social. Los intereses y fines personales se separan y diferencian de los económicos y objetivos, compartidos por muchos; mientras los primeros actúan como fines en sí mismos, los fines económicos, dirigidos o bien a la obtención de dinero o bien a la obtención de objetos con valor económico, son fines regulados por el proceso mecánico y autónomo de la economía monetaria. Las relaciones sociales devienen en relaciones formales: «La extensión de la economía monetaria desarrolla la reciprocidad mutua entre los seres humanos a la vez que se disuelven los elementos personales en las relaciones entre los individuos»» (Bilbao, 2003: 125).

Escindida la personalidad interna de la función social externa, mientras la primera se cierra sobre sí misma realizándose de espaldas al mundo y a los otros, la función social construye autónomamente la estructura social. La sociedad como conjunto de individuos libres y autónomos progresa en su 
forma funcional como agregado de autómatas dirigidos por los productos que crean; la relación entre las funciones, que es la verdadera relación social, es una relación entre los objetos que se poseen o los servicios que se prestan. El individuo que se relaciona con el exterior no es el yo real de la personalidad, sino el yo representado por la función; su relación con los otros es relación con funciones u objetos: «[...] los hombres no son sino sujetos de compensaciones entre prestación y contraprestación, regidas por normas objetivas, y todo lo que no pertenezca a esta pura objetividad, desaparece de ellas (Simmel, 1977 [1903]: 47-48).

\section{EL HOMBRE, UN SER COMPLEJO.}

Como hemos visto, el hombre es ser social y también ser insociable. Pero es que además su ser social tampoco es puramente social, dado que en él participan los aspectos y rasgos propios de la individualidad, de la dimensión interna del individuo; aquello de la persona que queda fuera de su vida social está inevitablemente influyendo en ella. De esta manera, al estar los individuos a la vez dentro y fuera de la sociedad, la relación que se establece entre aquéllos y ésta es similar a la que existe entre diferentes grupos sociales. Este hecho revela además la condición limítrofe que radica en la esencia humana: el hombre está al mismo tiempo dentro y fuera de la sociedad, siendo él mismo un límite que se trasciende -veremos más adelante que el hombre es límite y su trascendencia. Está dentro de la sociedad porque construye sociedad, porque tiene la necesidad y el deseo de relacionarse con los otros, pero al mismo tiempo está fuera porque también tiene deseo de ser individuo libre y diferente.

El Hombre, lo repetiremos varias veces, es ser dual y dialógico, natural y cultural, social e histórico, y además ser individual, autónomo y libre-que desea la libertad-. Es un ser complejo porque su centro anímico está compuesto por una pluralidad de fuerzas y energías contrarias y, en ocasiones, enfrentadas: es racional, pero también y al mismo tiempo irracional, uno y diverso, como la realidad misma. Y si no tenemos en cuenta todas estas dimensiones de lo humano, todo lo que el hombre es, y que es todo eso al mismo tiempo, poco nos estaremos aproximando al fondo de su naturaleza:

De lo que se trata es, ante todo, de esto: que el contenido social de la vida, aunque pueda ser explicado totalmente por los antecedentes sociales y por las relaciones sociales mutuas, debe considerarse al propio tiempo también, bajo la categoría de la vida individual, como vivencia del individuo y orientado enteramente hacia el individuo (Simmel, 1977 [1903]: 50).

También es un ser complejo porque es un ser ambivalente. En la unidad central de la vida individual se produce una tensión entre la energía interna, que 
es infinita y nunca llegamos a comprender por completo -porque tampoco se expresa por completo-, y su exteriorización visible, comprensible y finita. Este dualismo vital, que constituirá la «tragedia de la vida», sólo puede explicarse de manera indirecta a partir de los dualismos y contradicciones que encontramos en nuestra propia existencia. Simmel enumera distintas contradicciones: en la base fisiológica de nuestro ser se produce una contradicción entre la quietud y el movimiento, receptividad y productividad, que se prolonga hasta la base espiritual instándonos a aspirar a lo singular, que impele al dinamismo, o a lo general, que proporciona tranquilidad y empuja al estatismo. En la vida social el dualismo entre la quietud y lo general y el movimiento y lo singular se expresa como tensión entre la vida social y la vida individual. Así,

[la] historia entera de la sociedad podría reconstruirse a partir de la lucha, el compromiso, las conciliaciones lentamente conseguidas y rápidamente desbaratadas que surgen entre la tendencia a fundirnos con nuestro grupo social y a destacar fuera de él nuestra individualidad (Simmel, 1988 [1911]a: 27).

Reynner Franco dice en Intuición y concepto que para Simmel el hombre en tanto que individualización de la vida no está dividido en vida informe e ilimitada y vida formada y objetivada, no es continuo y con todo individualizado, sino que la esencia misma de la vida es contradictoria, dialógica: tiene una base dialéctica en la que reside su objetivo de trascendencia. La informidad es vida, pero la formalidad que se la opone también lo es, puesto que procede de la misma vida. En su definición la vida es lo relativo pero también lo absoluto, lo individual por limitado y lo continuo por ilimitado e informe; su «sí-misma» y también su contrario. Y como su base es dialéctica, tiene un destino trágico de autotrascendencia consistente en el establecimiento de límites que más tarde quebrantará: «voluntad de trascendencia» (Franco, 2008: 15).

\section{V. «ANTROPOLOGÍA DEL DEVENIR».}

Simmel hereda la idea romántica de que el hombre se crea a sí mismo en la interacción con el resto y con el mundo. El hombre no es sino que se hace en el mundo, junto a los otros, a la vez que hace mundo y sociedad; no tiene naturaleza, tiene historia.

El pensamiento de Simmel se estructura en torno a la idea de vida como fundamento último de la realidad y fuerza inagotable, inefable y en consecuencia informe que a todo dota de sentido. Dado que todo proceso, acontecimiento, hecho e incluso ley o idea está, en un momento inicial de su desarrollo, atravesado y condicionado por la vida como torrente dinámico e imparable, el ser está fuertemente ligado al devenir, siendo partes inseparables de una misma 
unidad existencial. Nada es -de un modo estático y definitivo-, todo está siendo -conforme está siendo atravesado por el dinamismo de la potencia vital.

Siguiendo a Marx, el hombre es ser histórico y ser social en la medida en que su historia es el relato vivo de su desarrollo: se hace haciendo. Simmel asume una concepción productiva-artística, social y en resumen no-esencialista de la naturaleza humana. Para sobrevivir y evolucionar el hombre tiene que trabajar en el mundo relacionándose además con los otros. De su acción productiva sobre y en el mundo obtiene una serie de productos -herramientas, vivienda, alimentos- que le sirven para satisfacer sus necesidades más básicas y vitales. A partir del trabajo con los otros el individuo produce lo necesario para la satisfacción de sus necesidades; se reconoce en aquello que produce porque contiene algo de sí en cuanto ser natural (Ritzer, 1997: 31).

De esta idea derivamos, siguiendo a Flamarique, que la única posibilidad de acercarnos al significado de la existencia humana es articular un esquema conceptual que se adapte a la dinámica propia de la vida. Nunca de un modo completo y definitivo, sino reconociendo la imposibilidad de apresar y aprehender el significado último de la vida y del hombre; es decir, reconociendo la falibilidad del conocimiento humano y la imposibilidad de alcanzar verdades absolutas acerca de un mundo y de una realidad, la humana, que estando en continua construcción y transformación no pueden conocerse según conceptos y definiciones acabadas (Flamarique, 2003: 143).

Cabe señalar aquí una importante idea que Simmel, con su lectura de la modernidad, realiza a la «antropología del devenir»: en la modernidad, tras el triunfo de la economía monetaria, el hombre ya no es ni se hace; ahora vale, tiene un precio. El nuevo orden instaurado por el dinero produce una transformación antropológica radical.

\section{EL HOMBRE COMO SER CULTURAL.}

Hemos dicho que para Simmel el hombre no es ser natural sino cultural -ha superado el estadio natural y primitivo penetrando en el estadio cultural-: el hombre es el animal que crea cultura, es decir, que objetiva y que se objetiva. A diferencia del animal no se ubica solamente en el ámbito de la naturaleza, sino que se enfrenta y opone a ella.

Simmel entiende la cultura como el proceso que lleva a cabo el alma para encontrarse consigo misma o como el viaje del alma hacia sí misma, revelando una fuerte influencia hegeliana. El espíritu -el sujeto humano-, diferenciándose de lo no viviente, no vive sólo en el instante presente sino que su ser se extiende sobre el pasado, lo que ha sido, y se proyecta hacia el futuro, lo que puede ser, porque a la vida en su tiempo presente le pertenece también el futuro como proyecto. La personalidad contiene una imagen futura de sí misma que en el proceso vital se desarrolla y construye alcanzando plena realidad; va de la 
posibilidad de desarrollo a la realización de la posibilidad. Entonces el desarrollo particular de cada una de las fuerzas anímicas tiende, aunque de forma independiente al resto, a la realización de la personalidad total, a la realización de la imagen futura de la personalidad que ella misma construye y contiene. Este proceso de despliegue es una primera forma de cultura: es individuo cultivado aquel para quien, habiéndose formado un saber o poder particular, habiendo potenciado sus fuerzas particulares, todos estos progresos sirven para el desarrollo y perfeccionamiento de su centralidad anímica. «[...] cultura es el camino desde la unidad cerrada, a través de la multiplicidad cerrada, hasta la unidad desarrollada» (Simmel, 1988 [1911]b: 206).

La evolución de la especie humana tiene su parte de desarrollo natural en la transmisión hereditaria para la adaptación a determinadas formas y contenidos de la existencia y en la organización físico-psíquica de las funciones biológicas. Pero cuando las fuerzas y energías humanas son orientadas y moduladas en función a determinados procesos teleológicos que tienden hacia un fin concreto del que éstas son medios, hablamos del estadio cultural de la evolución humana. Simmel considera que este estadio cultural del desarrollo evolutivo deriva causalmente del desarrollo natural de la especie, de modo que naturaleza y cultura «son sólo dos modos de consideración diversos de uno y el mismo acaecer» (Simmel, 1986 [1908]: 119).

«El hombre es el auténtico objeto de la cultura» (Simmel, 1986 [1908]: 121), es el único ser cuyo interior acoge una exigencia de perfección, siendo sus posibilidades de desarrollo anímico necesidades que apremian a la voluntad e inteligencia a su realización. Además, el desarrollo de sus metas no es posible sólo con el desenvolvimiento de sus fuerzas, sino que en un cierto momento requiere del apoyo de una técnica. Así, cultura es siempre cultura humana.

\section{VI.1. EL HOMBRE, ANIMAL QUE OBJETIVA.}

El individuo en cuanto vida individualizada y como ser cultural es un animal que crea «más vida», es decir, objetos culturales que contribuyen a su desarrollo anímico y al interés de la vida en manifestarse empíricamente. El hombre necesita de objetualidades culturales para el desarrollo de su personalidad igual que la vida para sus deseos de trascendencia -«voluntad de trascendencia».

La vida existe y se define en cuanto a la creación de «más vida», de algo que no es ella misma y a partir de lo cual se manifiesta. Esta creación de objetos y formas culturales para el desarrollo vital o anímico significa el punto de trascendencia de la vida sobre sí misma hacia su muerte, esto es, hacia su negación; el momento de nacimiento de la vida desde su mismo centro es también su momento de muerte. La dificultad generada a la hora de comprender esta identidad de la vida como vida y como algo más que vida es una dificultad 
lógica que nace de la división que realiza el intelecto entre dos identidades antagónicas que se sintetizan en una unidad, vida y lo que no es vida, que son en realidad una misma cosa (Simmel, 2000 [1918]: 309).

\section{VI.2. EL HOMBRE, ANIMAL QUE SE OBJETIVA}

Pero cuando el individuo crea «más vida» está dando comienzo al proceso de autonomización de los objetos culturales, que se terminan consolidando como «más que vida». El espíritu crea una serie de figuras, configuraciones y realidades que se independizan y alcanzan autonomía suficiente como para rechazar el alma subjetiva que las ha creado. Esto hace que el sujeto se vea atraído por los productos del derecho, de la ciencia o de la religión en tanto que partes escindidas de un yo anterior, material espiritual legado por generaciones pasadas, pero también experimenta hacia ellos cierto rechazo en la medida en que estos productos han adquirido autonomía y existen con independencia de los sujetos creadores (Simmel, 1988 [1911]: 205). El hombre como vida individualizada crea algo que le supera; se trasciende a sí mismo creando objetos y formas que le sirven para la manifestación externa o empírica de su fuerza vital interna y que finalmente terminan por independizarse y adquirir una lógica autónoma de desarrollo que introduce al individuo en una relación de sumisión y en una situación de enajenación.

Tanto el primer proceso de objetivación como este segundo responden a la esencia de la vida entendida como deseo de autotrascendencia. La vida crea desde sí misma «más vida», vida objetiva pero todavía no objetivada, que se convierte finalmente en «más que vida». Es decir: en la creación de productos objetivos para su manifestación externa la vida introduce vida en un objeto, vivificándolo y transformándolo; el objeto animado se configura como límite formal que la vida se pone a sí misma -la vida objetivada como límite de la vida subjetiva-; en su proceso continuo la vida termina por rebasar los límites que se ha puesto a sí misma.

Apliquemos a esta idea un esquema dialéctico-hegeliano: tenemos en primer lugar la tesis, la vida como potencia inmensa y fuente de realidad que dota de sentido a lo que es. En el núcleo interno de la vida está inscrito el deseo de trascendencia, asociado a la necesidad de manifestarse empíricamente. En su deseo de trascenderse la vida crea «más vida», pero este «más vida» se desconecta de la vida transformándose en «más que vida», que comparece como antitesis. Pero como la vida es una voluptuosa energía que siempre va a más, se constituye también como la fuerza que rebasa los límites formales que a sí misma se ha impuesto: es la sintesis. 


\section{VI.3. EL HOMBRE, ANIMAL ENAJENADO.}

El «más que vida» que la vida crea termina por adquirir una lógica de desarrollo independiente de las necesidades e intereses vitales y humanos imponiéndose sobre los sujetos creadores, ahora animales enajenados porque sometidos a las leyes objetivas instituidas por aquello que crean.

Como ser que objetiva, el hombre es ser cultural. En este sentido y a la vista del horizonte de objetivación que parece inherente a la esencia misma de la vida y al proceso de civilización, dado que el hombre es animal que crea cultura, es animal enajenado; como creador de objetividades que más tarde terminan por imponérsele es un animal que se enajena en su objetivo de alcanzar la perfección espiritual, fin del proceso cultural. Mejor aún, tiene un destino de enajenación: y es que el proceso de la «tragedia de la cultura» es inmanente al desarrollo cultural, porque en el seno mismo de la cultura está implícita la tensión original entre sujeto y objeto que en una dimensión más acelerada de desarrollo desemboca en imposición de lo objetivo y autonomización de las formas culturales.

El destino del hombre como ser cultural es trágico porque la gran empresa del espíritu -cultura- puede acabar en fracaso -y de hecho, así sucede en la modernidad. Tal y como explica Ramos Torres, en Hegel la salida del espíritu hacia el mundo para volver a sí mismo culmina de un modo positivo con la realización del espíritu absoluto. Simmel se aleja del optimismo hegeliano postulando la posibilidad de que el fin del viaje espiritual no sea la perfección del espíritu sino su objetivación y alienación, posicionándose así en una línea de pensamiento dialéctico-marxista (Ramos Torre, 2000: 51).

Cuando los productos culturales se autonomizan e independizan de los sujetos creadores avanzan, motivados por la ley de desarrollo de las formas culturales, para lograr su perfección. Esta perfección, habiéndose desentendido de la necesidad subjetiva de perfeccionamiento interno, llega a superar las posibilidades de acceso de los sujetos a dicho ritmo de desarrollo, de modo que progresan con una celeridad e intensidad de perfeccionamiento mucho mayor que de la que los sujetos creadores son capaces. Esta es la clave y culminación de la «tragedia de la cultura moderna»: la «hipertrofia de la cultura objetiva», paralela a la «atrofia de la cultura subjetiva»:

Hay obras humanas de una perfección inalcanzable a las cuales, precisamente a causa de esta redondez sin lagunas, no tenemos ningún acceso o que, por ello, no tienen ningún acceso a nosotros. Una obra semejante permanece, digámoslo así, en su lugar, desde el cual no cabe transportarla a nuestros dominios; es una perfección solitaria hacia la que quizá podemos dirigirnos, pero que no podemos llevar con nosotros para alzarnos en ella a la perfección de nosotros mismos (Simmel, 1988 [1911]b: 217). 


\section{El HOMBRE COMO LÍMITE QUE SE LIMITA.}

«Del hecho de que dispongamos de límites siempre y por doquier, puede deducirse que somos también límites» (Simmel, 2000 [1918]: 297). Puesto que el alma humana es vida individualizada y la vida tiene deseo de trascenderse, el hombre tiene deseo de trascenderse, de superarse en la idea que se hace de sí. El hombre se limita siendo al mismo tiempo límite y aquello que lo supera. A este respecto el hombre como vida individualizada padece también la «tragedia de la vida»: el deseo de la vida de ponerse límites la dirige a su destrucción; los límites son necesarios como medio de expresión de la vida y como vía de canalización del torrente vital hacia la satisfacción de unos fines determinados, pero destruyen la vida y la convierten en «no-vida». No obstante, a pesar de que sean necesarios no son nunca definitivos ni absolutos, de manera que pueden modificarse, destruirse y reconstruirse.

El reconocimiento de un límite invita a su trascendencia, y esa trascendencia confirma su realidad como límite: el tener conciencia de los límites implica su trascendencia. El individuo reconoce la limitación cuando la supera, y como adquiere conciencia de sí mismo en el ejercicio de autoconsciencia, y en este ejercicio se supera a sí mismo, se niega a sí mismo construyendo una nueva imagen de sí que transgrede la imagen anterior -la imagen ideal de la vida como deber ser al que aspira-. El hombre es límite y es también aquello que trasciende el límite: hombre efectivo, vida petrificada en un cuerpo sensible, y al mismo tiempo conciencia que piensa el deber ser hacia el cual ha de orientar su desarrollo; y es también el agente ejecutor de esa idea, transgresor del límite que se ha puesto para sí (Simmel, 2000 [1918]: 301).

\section{VII.1. PUENTE Y PUERTA.}

La imagen que el hombre se hace de las cosas, a la vista de su condición de «unidad en la diversidad» o unidad diversa, expresa una ambigüedad según la cual parecen éstas estar ligadas entre sí de acuerdo a un todo que aunque total y unitario está articulado, pero se presentan en el espacio separadas las unas de las otras. El hombre, en la tarea de representación e interpretación del mundo, es el encargado de separar o ligar las cosas que son. Así, cuando aísla conceptualmente dos objetos para su análisis y los designa como objetos distintos, refiere primeramente al estado de unión que hay entre ellos, y en el acto de sacarlos del orden de las cosas del mundo los diferencia a su vez del resto de cosas, con las que se presupone una unión originaria. Del mismo modo, cuando une dos objetos en función a determinados criterios lógicos presupone una confrontación previa.

El hombre por tanto tiene la capacidad de establecer uniones entre los objetos del mundo y también de romper esos caminos de convergencia para 
distinguirlos y distanciarlos. Este proceso de unión o desunión se produce en un primer momento de manera subjetiva, y sólo cuando se han establecido caminos de convergencia o puntos de confrontación empíricos, perceptibles para el observador externo, se convierten en realidad objetiva.

El hombre es el animal que construye caminos de ligazón que superan las resistencias físicas y espaciales que median entre las cosas, y también el que pone esas resistencias: es puente y puerta para las cosas del mundo y para el mundo mismo en cuanto a su relación con él: «[...] el puente muestra cómo el hombre unifica la escisión del ser meramente natural, la puerta cómo separa la unidad uniforme y continua del ser natural» (Simmel, 1986 [1909]: 33).

«El hombre es ser que liga, que siempre debe separar y que sin separar no puede ligar [...] Y del mismo modo el hombre es el ser fronterizo que no tiene ninguna frontera» (Simmel, 1986 [1909]: 34). Igual que la puerta crea fronteras que delimitan el mundo real, pero también tiene la capacidad de destruir esas fronteras y volver a unificar elementos dispersos; además, él mismo puede ponerse fronteras y rebasarlas en su condición de frontera, porque esa es para Simmel la esencia del ser humano (Ramos Torre, 2000: 57).

\section{EL HOMBRE, UN SER CREATIVO.}

El hombre un ser que para tomar distancia de su estadio natural crea arte y cultura; un ser creador y creativo. En su condición de creador descansan sus posibilidades de adaptación e imposición sobre un mundo que se le presenta como extraño y hostil y frente al cual tiene que luchar para asegurar su supervivencia.

En Sobre la libertad Simmel explica en qué consiste la creatividad del hombre y cómo está ligada a un espacio de innovación y libertad ajeno a las leyes mecanicistas y deterministas que rigen la historia. La vida individual, el individuo o «la existencia viva emocional» (Simmel, 2007 [1918]: 318) genera estados y procesos nuevos no a partir de estados anteriores y por tanto predecibles desde éstos, sino a partir del total de todos ellos, es decir, del total de la vida. En la vida histórica, por tanto, no hay una ley o un principio general que predetermine la aparición de sucesos futuros. Pero no debemos pasar por alto el hecho de que la vida humana se volvería insostenible si no fuese posible prever ciertos acontecimientos que derivan de ciertos estados mentales o emocionales, confiando en que de hecho así ocurrirá. Las relaciones humanas se regulan por el conocimiento mutuo que los individuos tienen del otro y por la confianza en que el otro actuará de acuerdo con lo establecido -por la norma social- o lo previsto -por leyes positivas que preparan el curso de los acontecimientos físicos. A pesar de que concebimos al otro y a nosotros mismos como sujetos libres y creativos podemos estar seguros del desarrollo de ciertos sucesos que se ajustan a ciertas disposiciones o estados de ánimo que suponemos en el otro: 
Frecuentemente actuamos como si estuviéramos seguros de los futuros actos y pensamientos de los demás, y no de manera hipotética y con reservas, sino categóricamente y la mayoría de las veces sin que en este conocimiento previo existiera la mínima duda de que pudiera ser diferente, de que el otro aprovechase su libertad para diferir (Simmel, 2007 [1918]: 322).

El hombre es un ser creativo porque no crea los objetos de la cultura, del arte, de la ciencia, de la religión, etc. de acuerdo a leyes externas a sí mismo, de manera que podría predecirse qué creaciones se producirán en un futuro en determinado grupo social según el análisis de las ya producidas, sino que los crea según su fuerza interna y vital, de acuerdo con una ley vital individual que hace del individuo un individuo único e irrepetible, un genio creador. Pero, evidentemente, no todos somos genios; el mundo en que vivimos no es un mundo habitado por Goethes, Rodines o Miguel Ángeles. En la modernidad, como veremos en el siguiente punto, el hombre se transforma en animal enajenado precisamente porque pierde su condición de ser creativo: el individuo moderno, que crea según las leyes que le imponen las formas objetivas sin posibilidad de manifestar empíricamente su intimidad, no es libre: no es ser creativo sino animal enajenado, no agente cultural sino sujeto paciente de los dictámenes de una «cultura objetiva» que se le ha escapado de las manos.

\section{EL INDIVIDUO MODERNO COMO SUJETO CONSUMIDOR.}

El individuo moderno es animal enajenado porque se ha convertido en sujeto consumidor. El progreso cultural deviene en la época moderna en sistema de explotación y consumo. Según Bilbao el consumidor es el sujeto racional moderno que el nuevo orden de lo objetivo, esto es, el triunfo de la «cultura objetiva» sobre la «cultura subjetiva», produce en la modernidad. Un sujeto que es libre a nivel interno, para pensarse y pensar el mundo, pero dependiente, enajenado a nivel externo u objetivo, para con los otros y para realizar su libertad sobre el mundo -transformando con ello el actual estado de cosas-.

La libertad del sujeto consumidor se mide según la satisfacción de su deseo; pero este deseo ya nada tiene que ver con el impulso vital para el perfeccionamiento espiritual, sino con la conquista del dinero: es libertad económica para la obtención de dinero, y no libertad vital, humana, para la realización de la imagen ideal que se tiene de sí. El mundo externo es para este nuevo individuo un mundo instrumental que le sirve como medio para la satisfacción de su deseo económico. El consumidor es el sujeto racional y racionalizador del mundo en torno del cual gira la organización del sistema de producción y consumo del mercado capitalista.

La figura del consumidor como centro organizador del mercado a partir del cual se articula todo el mundo de la producción marca el paso de la teoría 
económica clásica y su idea de la «mano invisible» como elemento rector de las leyes objetivas de la oferta y la demanda a la teoría económica moderna: de la teoría objetiva del valor a la teoría subjetiva que pone el acento no ya en el productor, sino en el consumidor:

La armonía de intereses ya no tiene su origen en la acción causal del individuo, bajo la égida de la mano invisible, sino en la figura del individuo que se relaciona con las cosas impulsado por su deseo, por medio del cálculo monetario. El consumidor es la omnipresente figura que determina todo aquello que acontece. La sociedad moderna aparece como una organización democráticamente regida por el consumidor (Bilbao, 2000: 136).

Nos dice Marinas que Simmel, siguiendo la pauta marcada por Marx y centrándose en los elementos y procesos del consumo, se encuentra con que en la modernidad el sujeto del consumo ya no es el individuo particular sino el estilo de vida, entendiendo por tal el conjunto de las relaciones que el individuo mantiene con los otros, con los productos objetivos que crea, con el mundo y con las representaciones e imágenes que se hace de éste. Y por el otro lado el objeto de consumo ya no es el bien de consumo sino el conjunto de pautas, relatos o signos culturales que lo dotan de sentido y significado. Bajo esta nueva forma de consumo, de la que Simmel desvela su lado oculto, la vida social se objetiva e impersonaliza. Su lado oculto, aclara Marinas, porque es aquello que no ha sido desvelado, que se encuentra más allá de lo evidente y destruye todo sentido de evidencia. El lado oculto de la realidad del consumo tiene que ver con la globalización e impersonalización de las relaciones sociales, con su determinación cultural, con la objetivación de las emociones y con el carácter inconsciente e irracional que adquieren todos sus procesos (Marinas, 2000: 185).

A nivel psicológico el sujeto consumidor es un sujeto enajenado porque no es capaz de afirmarse como yo autónomo sobre el mundo. Muy al contrario se representa como conciencia pensante unida a objetos pensados que no forman una unidad férrea como la que se produce en el estado psicológico del disfrute, sino que existen como entidades independientes y externas pero adheridas al yo consciente. El espacio existencial del sujeto enajenado se ve amenazado por los objetos que le enajenan debido a un proceso de refinamiento y especialización de las necesidades y los deseos: ya no es el sujeto el que otorga valor a los objetos por el interés que despiertan en su conciencia, sino que el valor que le ha sido otorgado a un objeto configurándolo como objeto peculiar y único, se ha convertido en valor por sí mismo, es decir, se ha abstraído de la representación del sujeto y se ha convertido en un valor «que va más allá de la facultad de ser disfrutado» (Simmel, 2003 [1900]: 26). 


\section{CONCLusión.}

Reconstruyendo las tesis principales de la antropología filosófica de Simmel hemos trazado un retrato bastante completo de la anatomía del individuo moderno: un individuo en tensión constante consigo mismo y con la sociedad; que tiene deseo de alejarse de la sociedad pero que al tiempo necesita de ella para sobrevivir, que quiere distinción pero que tiende a la socialización; un ser complejo y dinámico sumido en una realidad caótica y cambiante; un problema de estructura histórica, un problema que se ha de buscar por sí mismo solución; un creador cultural aplastado por su propia obra; objetivador objetivado, límite autolimitado.

Pero hemos visto además cómo el dinero y el sistema capitalista que trae consigo actúan de forma decisiva en la configuración de dicho tipo de hombre. En este sentido la modernidad, en cuanto época del triunfo del dinero como elemento rector de toda relación y de todo intercambio, es una época antihumanista o no-humana en la que se confirma el triunfo de la «cultura objetiva». Y el sistema capitalista es la estructura económico-social que confirma la anatomía del nuevo individuo tanto a nivel individual como a nivel social.

En este análisis de la antropología filosófica de Georg Simmel, por tanto, hemos podido completar una imagen del hombre moderno, y además nos sirve como corolario para una crítica al sistema capitalista de consumo y a la sociedad que produce.

\section{REFERENCIAS}

BILBAO, A. 2000. El dinero y la libertad monetaria. En: Revista española de investigaciones sociológicas (REIS), núm. 89, pp. 119-139.

FLAMARIQUE, L. La crítica del conocimiento histórico. La primera respuesta de Simmel al conflicto entre ley y vida. En Flamarique, L., Kroker, R. y Múgica Martinena, F. 2003. Georg Simmel: Civilización y diferenciación social (I). Serie clásicos de sociología. Cuadernos de anuario filosófico, Servicio de publicaciones de la Universidad de Granada.

FRANCO, R. 2008. Intuición y concepto. Ampliación simmeliana de la epistemología de Nietzsche. En: Euphyía, Revista de Filosofía, núm. 2, pp. 9-24.

KROKER, R. El concepto de diferenciación social dentro del desarrollo del pensamiento simmeliano. En Flamarique, L., Kroker, R. y Múgica Martinena, F. 2003. Georg Simmel: Civilización y diferenciación social (I). Serie clásicos de sociología. Cuadernos de anuario filosófico, Servicio de publicaciones de la Universidad de Granada.

MARINAS, J.M. 2000. Simmel y la cultura del consumo. En: Revista española de investigaciones sociológicas (REIS), núm. 89, pp. 183-218. 
MUNDO, D. Introducción a: Simmel, G. 2015. El secreto y las sociedades secretas. Madrid: Editorial Sequitur.

ORTEGA Y GASSET, J. Conocimiento del hombre. Para una psicología del hombre interesante. En: Ortega y Gasset, J. 2015. Las Atlántidas y otros textos antropológicos. Edición de José Ramón Carriazo Ruiz. Madrid: Tecnos. pp. 241-256. (or. 1925)

RAMOS TORRE, R. 2000. Simmel y la tragedia de la cultura. En: Revista española de investigaciones sociológicas (REIS), núm. 89, pp. 37-71.

RITZER, G. 1997. Teoría sociológica contemporánea. México: McGraw-Hill. Traducción de Casado Rodríguez, M.T., revisión técnica de Almarcha Barbado, A.

SAFERSTEIN, E. A. 2010. El individuo en la modernidad. Los vaivenes de la acción recíproca en Georg Simmel. A Parte Rei, Revista de Filosofía: núm. 70.

SIMMEL, G. 1977. Sociología: Estudios sobre las formas de socialización. Madrid: Biblioteca de la Revista de Occidente. (or. 1908)

__ _ Las grandes ciudades y la vida intelectual. En: Gutiérrez Girardot, R. (Ed.) 1978. Discusión II. Teorías sobre los sistemas sociales. Barcelona: Barral Editores. (or. 1903)

___ _ Puente y puerta. En: Mas, S. (Ed.) 1986. El individuo y la libertad. Ensayos de la crítica de la cultura. Barcelona: Ediciones Península. pp. 29-34 (or. 1909)

___ _ . De la esencia de la cultura. En: Mas, S. (Ed.) 1986. El individuo y la libertad. Ensayos de la crítica de la cultura. Barcelona: Ediciones Península. pp. 119-128 (or. 1908)

___ L L La moda. En: Mas, S (Ed.) 1988. Sobre la aventura. Ensayos filosóficos. Barcelona: Ediciones Península. (or. 1911) (a)

___ El El concepto y la tragedia de la cultura. En: Mas, S (Ed.) 1988. Sobre la aventura. Ensayos filosóficos. Barcelona: Ediciones Península. (or. 1911) (b)

—__ . 2000. La trascendencia de la vida. En: Revista española de investigaciones sociológicas (REIS), núm. 89, pp. 297-313. (or. 1918)

___ 2003. Filosofía del dinero. Monereo Pérez, J.L. (Ed.). Granada - Editorial Comares. (or. 1900)

___ Sobre la libertad. En: Sabido Ramos, O. (Ed.) 2007. Georg Simmel. Una revisión contemporánea. Barcelona-México: Anthropos. (or. 1918)

EDUARDo GutiérREZ GutiérREZ es doctorando en filosofía por la Universidad de Valladollid

Lineas de investigación

Antropología filosófica/ Filosofía de la cultura/ Sociología. 
Publicaciones recientes

(2016), Vértigo, Valladolid, La Sombra de Caín.

(2016), Georg Simmel: Un sociólogo moderno y un sociólogo de la modernidad, Madrid: Ápeiron Ediciones.

(2017), "El barbarismo de las masas visto desde la perspectiva de tres "pensadores de lo social': Gustave Le Bon, Georg Simmel y José Ortega y Gasset”, Agora papeles de Filosofía (núm. 36/2, pp. 101-132).

Dirección postal:

C/ Los Lienzos 43-45, $1^{\circ} \mathrm{A}$. Medina de Rioseco - Valladolid (47800).

Email: edukobain@gmail.com 
